\title{
Intermetallic REPtZn Compounds with TiNiSi-type Structure
}

\author{
Trinath Mishra and Rainer Pöttgen \\ Institut für Anorganische und Analytische Chemie, Universität Münster, Corrensstraße 30, \\ 48149 Münster, Germany \\ Reprint requests to R. Pöttgen. E-mail: pottgen@uni-muenster.de
}

Z. Naturforsch. 2011, 66b, 671-676; received May 27, 2011

\begin{abstract}
The equiatomic rare earth compounds $R E \mathrm{PtZn}(R E=\mathrm{Y}, \mathrm{Pr}, \mathrm{Nd}, \mathrm{Gd}-\mathrm{Tm})$ were synthesized from the elements in sealed tantalum tubes by high-frequency melting at $1500 \mathrm{~K}$ followed by annealing at $1120 \mathrm{~K}$ and quenching. The samples were characterized by powder X-ray diffraction. The structures of four crystals were refined from single-crystal diffractometer data: TiNiSi type, Pnma, $a=$ 707.1(1), $b=430.0(1), c=812.4(1) \mathrm{pm}, w R 2=0.066,602 F^{2}, 21$ variables for $\operatorname{PrPt}_{1.056} \mathrm{Zn}_{0.944} ; a=$ 695.2(1), $b=419.9(1), c=804.8(1) \mathrm{pm}, w R 2=0.041,522 F^{2}, 21$ variables for $\mathrm{GdPt}_{0.941} \mathrm{Zn}_{1.059}$; $a=688.2(1), b=408.1(1), c=812.5(1) \mathrm{pm}, w R 2=0.041,497 F^{2}, 22$ variables for $\mathrm{HoPt}_{1.055} \mathrm{Zn}_{0.945}$; $a=686.9(1), b=407.8(1), c=810.4(1) \mathrm{pm}, w R 2=0.061,779 F^{2}, 20$ variables for ErPtZn. The single-crystal data indicate small homogeneity ranges $R E \mathrm{Pt}_{1 \pm x} \mathrm{Zn}_{1 \pm x}$. The platinum and zinc atoms build up three-dimensional [PtZn] networks $(265-269 \mathrm{pm} \mathrm{Pt}-\mathrm{Zn}$ in $\mathrm{ErPtZn})$ in which the erbium atoms fill cages with coordination number $16(6 \mathrm{Pt}+6 \mathrm{Zn}+4 \mathrm{Er})$. Bonding of the erbium atoms to the [PtZn] network proceeds via shorter RE-Pt distances, i. e. $288-293$ pm in ErPtZn.
\end{abstract}

Key words: Intermetallics, Rare Earth Compounds, Crystal Structure

\section{Introduction}

A huge number of equiatomic intermetallic RETX compounds $(R E=$ rare earth metal, $T=$ transition metal, $X=$ element of the $3^{\text {rd }}, 4^{\text {th }}$, or $5^{\text {th }}$ main group) has been synthesized and structurally characterized in the last forty years. The basic crystallographic data of the phases are compiled in the Pearson data base [1] Most of these phases crystallize with the hexagonal $\mathrm{ZrNiAl}$ [2-4] or orthorhombic TiNiSi [5] structure types. The size of the $T$ and $X$ atoms and the valence electron concentration have an important influence on the structure and physical properties of the compounds [6].

The $T$ and $X$ atoms build up three-dimensional [TX] polyanionic networks with substantial covalent $T-X$ bonding. This has been manifested by electronic structure calculations for diverse representatives of both structure types [7-9, and refs. cited therein]. Recent investigations on related equiatomic compounds have shown that the $X$ positions within the covalently bonded networks can be substituted by magnesium [10], cadmium [11, 12], and even zinc [11,13]. The resulting compounds show covalent $T-\mathrm{Mg}, T-\mathrm{Cd}$, and $T-\mathrm{Zn}$ bonding within the [TX] networks [14]. Substitution of the $X$ position by divalent magnesium, cad- mium or zinc leads to a decrease of the valence electron concentration, and one can effectively modify the physical properties while keeping the crystal structure. To give an example, in going from EuAuGe [15] via EuAuIn [16] to EuAuZn [13], the magnetic ordering temperature changes from 34 via 21 to $51 \mathrm{~K}$.

Of the compounds with divalent magnesium, cadmium and zinc, the zinc-containing compounds have only scarcely been studied. Few intermetallic compounds $R E N i Z n$ and $R E P d Z n$ [11,17-19] with $\mathrm{ZrNiAl}$-type structure as well as some $\mathrm{KHg}_{2} / \mathrm{TiNiSi}$ type compounds with copper, silver and gold as transition metal component [20,21] have been reported. The first investigations of the properties of such materials showed interesting magnetic behavior. CeNiZn [18] is an intermediate-valent cerium compound, EuAuZn [13] orders ferromagnetically at the comparatively high Curie temperature of $51.1 \mathrm{~K}$, and YbPtZn [22] shows an onset of a heavy fermion state which orders magnetically at $1.35 \mathrm{~K}$. CePtZn [23, 24] is a dense Kondo system, and its antiferromagnetic ordering has been detected at $T_{\mathrm{N}}=1.7 \mathrm{~K}$. SmPtZn [25] shows a comparatively high Curie temperature of $48 \mathrm{~K}$. The Laves phase $\mathrm{EuRh}_{1.2} \mathrm{Zn}_{0.8}$ [26] orders ferromagnetically at $95 \mathrm{~K}$, and magnetocaloric investigations have shown that $\mathrm{EuRh}_{1.2} \mathrm{Zn}_{0.8}$ has a quite high normal- 


\begin{tabular}{|c|c|c|c|c|c|c|}
\hline Compound & $a(\mathrm{pm})$ & $b(\mathrm{pm})$ & $c(\mathrm{pm})$ & $V\left(\mathrm{~nm}^{3}\right)$ & Ref. & Table 1. Lattice parameters \\
\hline$\overline{\mathrm{YPtZn}}$ & $695.0(2)$ & $414.0(1)$ & $813.3(1)$ & 0.2340 & This work & the equiatomic $R E \mathrm{PtZn}$ \\
\hline LaPtZn & $719.2(2)$ & $438.4(1)$ & $816.0(3)$ & 0.2568 & [24] & $(R E=\mathrm{Y}, \quad \mathrm{La}-\mathrm{Nd}, \quad \mathrm{Sm}-\mathrm{Lu})$ \\
\hline CePtZn & $707.4(2)$ & $436.0(1)$ & $810.4(1)$ & 0.2499 & [24] & \\
\hline CePtZn & $706.89(19)$ & $435.08(15)$ & $809.71(16)$ & 0.2490 & [23] & \\
\hline PrPtZn & $707.2(2)$ & $430.4(1)$ & $810.8(3)$ & 0.2467 & This work & \\
\hline $\operatorname{PrPt}_{1.056} \mathrm{Zn}_{0.944^{\mathrm{a}}}$ & $707.1(1)$ & $430.0(1)$ & $812.4(1)$ & 0.2470 & This work & \\
\hline NdPtZn & $703.7(2)$ & $428.1(1)$ & $812.1(1)$ & 0.2447 & This work & \\
\hline SmPtZn & $701.5(2)$ & $422.0(1)$ & $811.1(3)$ & 0.2401 & [25] & \\
\hline EuPtZn & $727.8(3)$ & $443.7(1)$ & $781.7(3)$ & 0.2524 & [13] & \\
\hline GdPtZn & $696.9(3)$ & $418.8(1)$ & $809.1(4)$ & 0.2362 & This work & \\
\hline $\mathrm{GdPt}_{0.941} \mathrm{Zn}_{1.059^{\mathrm{a}}}$ & $695.2(1)$ & $419.9(1)$ & $804.8(1)$ & 0.2349 & This work & \\
\hline TbPtZn & $695.9(2)$ & $414.7(1)$ & $812.7(2)$ & 0.2345 & This work & \\
\hline DyPtZn & $691.52(9)$ & $411.21(7)$ & $811.9(2)$ & 0.2309 & This work & \\
\hline HoPtZn & $688.4(2)$ & $408.4(1)$ & $811.4(2)$ & 0.2281 & This work & \\
\hline $\mathrm{HoPt}_{1.055} \mathrm{Zn}_{0.945^{\mathrm{a}}}$ & $688.2(1)$ & $408.1(1)$ & $812.5(1)$ & 0.2282 & This work & \\
\hline ErPtZn & $687.0(2)$ & $407.9(2)$ & $811.1(3)$ & 0.2273 & This work & \\
\hline $\mathrm{ErPtZn}^{\mathrm{a}}$ & $686.9(1)$ & $407.8(1)$ & $810.4(1)$ & 0.2270 & This work & \\
\hline TmPtZn & $687.2(2)$ & $406.0(1)$ & $809.6(3)$ & 0.2259 & This work & \\
\hline YbPtZn & $684.2(1)$ & $405.7(1)$ & $810.3(1)$ & 0.2249 & [22] & \\
\hline LuPtZn & $681.6(2)$ & $402.0(1)$ & $812.9(2)$ & 0.2227 & {$[22]$} & a Single crystal data. \\
\hline
\end{tabular}

ized relative cooling power of $103 \mathrm{~J} \mathrm{~K}^{-1} \mathrm{~T}^{-1}$ for $\Delta H=$ $5 \mathrm{~T}$, classifying it as an interesting material for cooling applications.

In continuation of our phase analytical studies on the $R E$ AuZn series $[13,21]$ we have now investigated the corresponding platinum-based compounds. The synthesis protocols and the complete structural characterization of the equiatomic REPtZn $(R E=\mathrm{Y}, \mathrm{Pr}, \mathrm{Nd}$, $\mathrm{Gd}-\mathrm{Tm})$ compounds are reported herein.

\section{Experimental Section}

Synthesis

Starting materials for the preparation of the REPtZn $(R E=\mathrm{Y}, \mathrm{Pr}, \mathrm{Nd}, \mathrm{Gd}-\mathrm{Tm})$ samples were ingots of the rare earth elements (Johnson Matthey, smart elements, or Kelpin), platinum powder (Degussa-Hüls), and zinc granules (Merck), all with stated purities better than $99.9 \%$. The rare earth metal ingots were cut into smaller pieces and arc-melted [27] to buttons under an argon atmosphere of $c a$. 800 mbar. The argon was purified before with molecular sieves, silica gel, and titanium sponge (900 K). Subsequently, the rare earth buttons, the platinum powder and the pieces of the zinc granules (1:1:1 atomic ratio) were sealed in tantalum tubes under an argon pressure of 800 mbar. The tubes were then placed in a water-cooled sample chamber of a high-frequency furnace (Hüttinger Elektronik, Freiburg, Germany, Typ TIG 2.5/300) under flowing argon [28], heated up to $1500 \mathrm{~K}$ for about $5 \mathrm{~min}$ and then annealed at $1120 \mathrm{~K}$ for another $4 \mathrm{~h}$, followed by quenching. The temperature was controlled through a Sensor Therm Methis MS09 pyrometer with an accuracy of $\pm 30 \mathrm{~K}$. The samples did not react with the tantalum tube.
The gray polycrystalline REPtZn samples are stable in air over months.

\section{EDX data}

Semiquantitative EDX analyses on the crystals investigated on the diffractometer and on the bulk samples were carried out by use of a Zeiss EVO ${ }^{\circledR}$ MA10 scanning electron microscope in variable pressure mode with the rare earth trifluorides, platinum and zinc as standards. The bulk samples were previously embedded in a methylmetacrylate matrix, and the surface was polished with diamond and silica paste. The surface remained unetched for the EDX measurements. The experimentally observed compositions were close to the ideal ones. No impurity elements heavier than sodium (detection limit of the instrument) were found.

\section{X-Ray diffraction}

The REPtZn samples were characterized by Guinier patterns (imaging plate detector, Fuji-film BAS-1800 readout system) with $\mathrm{Cu} K_{\alpha 1}$ radiation and $\alpha$-quartz ( $a=491.30$ and $c=540.46 \mathrm{pm})$ as the internal standard. The orthorhombic lattice parameters (Table 1) were refined by a least-squares routine. Proper indexing was ensured through intensity calculations [29].

Small irregularly shaped single crystals of $R E \mathrm{PtZn}(R E=$ $\mathrm{Pr}, \mathrm{Gd}, \mathrm{Ho}, \mathrm{Er}$ ) were isolated from the crushed samples. They were glued to quartz fibers and investigated on a Buerger precession camera (white Mo radiation, Fuji-film imaging plate) in order to check the quality for intensity data collection. The data sets were collected at room temperature by use of two four-circle diffractometers (CAD4) with graphitemonochromatized $\operatorname{Mo} K_{\alpha}\left(\operatorname{Ag} K_{\alpha}\right)$ radiation and a scintilla- 
Table 2. Crystallographic data and structure refinements of $R E \operatorname{PtZn}(R E=\operatorname{Pr}, \mathrm{Gd}, \mathrm{Ho}, \mathrm{Er})$ with space group Pnma, Z $=4$.

\begin{tabular}{|c|c|c|c|c|}
\hline Refined composition & $\operatorname{PrPt}_{1.056} \mathrm{Zn}_{0.944}$ & $\mathrm{GdPt}_{0.941} \mathrm{Zn}_{1.059}$ & $\mathrm{HoPt}_{1.055} \mathrm{Zn}_{0.945}$ & ErPtZn \\
\hline Molar mass, $\mathrm{g} \mathrm{mol}^{-1}$ & 408.50 & 409.93 & 432.52 & 427.72 \\
\hline Crystal size, $\mu \mathrm{m}^{3}$ & $20 \times 30 \times 40$ & $20 \times 25 \times 50$ & $20 \times 35 \times 50$ & $20 \times 40 \times 50$ \\
\hline Lattice parameters & Table 1 & Table 1 & Table 1 & Table 1 \\
\hline Calculated density, $\mathrm{g} \mathrm{cm}^{-3}$ & 11.00 & 11.53 & 12.59 & 12.50 \\
\hline Radiation & $\operatorname{Mo} K_{\alpha}$ & $\operatorname{Ag} K_{\alpha}$ & $\operatorname{Ag} K_{\alpha}$ & $\operatorname{Mo} K_{\alpha}$ \\
\hline$\lambda, \mathrm{pm}$ & 71.073 & 56.086 & 56.086 & 71.073 \\
\hline Absorption coeff., $\mathrm{mm}^{-1}$ & 87.8 & 50.4 & 58.3 & 108.0 \\
\hline Transm. ratio, $\max / \min$ & $0.309 / 0.221$ & $0.267 / 0.236$ & $0.302 / 0.180$ & $0.517 / 0.211$ \\
\hline$F(000), \mathrm{e}$ & 679 & 676 & 711 & 704 \\
\hline$\theta$-range, deg. & $3-35$ & $3-26$ & $3-26$ & $3-40$ \\
\hline Range in $h k l$ & $\pm 11, \pm 6, \pm 13$ & $\pm 10, \pm 6, \pm 12$ & $\pm 10, \pm 6, \pm 12$ & $\pm 12, \pm 7, \pm 14$ \\
\hline Total no. reflections & 4079 & 3508 & 5053 & 5344 \\
\hline Independent reflections / $R_{\text {int }}$ & $602 / 0.122$ & $522 / 0.068$ & $497 / 0.101$ & $779 / 0.095$ \\
\hline Reflections with $I \geq 2 \sigma(I) / R_{\sigma}$ & $518 / 0.052$ & $439 / 0.035$ & 414 / 0.039 & $628 / 0.042$ \\
\hline Data / ref. parameters & $602 / 21$ & $522 / 21$ & $497 / 22$ & $779 / 20$ \\
\hline Goodness-of-fit on $F^{2}$ & 1.158 & 1.065 & 1.143 & 1.071 \\
\hline$R 1 / w R 2$ for $I \geq 2 \sigma(I)$ & $0.031 / 0.063$ & $0.026 / 0.039$ & $0.022 / 0.038$ & $0.027 / 0.057$ \\
\hline$R 1 / w R 2$ for all data & $0.040 / 0.066$ & $0.040 / 0.041$ & $0.034 / 0.041$ & $0.040 / 0.061$ \\
\hline Extinction coefficient & $0.0023(3)$ & $0.0050(3)$ & $0.0104(4)$ & $0.0043(3)$ \\
\hline Largest diff. peak / hole, e $\AA^{-3}$ & $3.42 /-4.81$ & $2.36 /-3.11$ & $2.26 /-2.31$ & $3.47 /-4.15$ \\
\hline
\end{tabular}

Table 3. Atomic coordinates and anisotropic displacement parameters $\left(\mathrm{pm}^{2}\right)$ for $R E \mathrm{PtZn}(R E=\mathrm{Pr}, \mathrm{Gd}, \mathrm{Ho}$, Er). All atoms lie on Wyckoff sites $4 c(x 1 / 4 z)$. $U_{\text {eq }}$ is defined as one third of the trace of the orthogonalized $U_{\mathrm{ij}}$ tensor. $U_{12}=U_{23}=0$.

\begin{tabular}{|c|c|c|c|c|c|c|c|}
\hline Atom & $x$ & $z$ & $U_{11}$ & $U_{22}$ & $U_{33}$ & $U_{13}$ & $U_{\mathrm{eq}}$ \\
\hline \multicolumn{8}{|l|}{$\overline{\operatorname{PrPt}_{1.056(5)} \mathrm{Zn}_{0.944(5)}}$} \\
\hline $\operatorname{Pr}$ & $0.03090(8)$ & $0.69141(7)$ & $72(3)$ & $100(3)$ & $95(2)$ & $-7(2)$ & $89(1)$ \\
\hline $\mathrm{Pt}$ & $0.26488(6)$ & $0.38785(5)$ & $80(2)$ & $89(2)$ & $118(2)$ & $18(1)$ & $96(1)$ \\
\hline $0.944(5) \mathrm{Zn}+0.056(5) \mathrm{Pt}$ & $0.64969(17)$ & $0.43158(14)$ & $156(6)$ & $106(6)$ & $93(6)$ & $-27(4)$ & $118(4)$ \\
\hline \multicolumn{8}{|l|}{$\mathrm{GdPt}_{0.941(5)} \mathrm{Zn}_{1.059(5)}$} \\
\hline Gd & $0.03479(8)$ & $0.68823(7)$ & $90(2)$ & $108(2)$ & $106(2)$ & $-6(2)$ & $101(2)$ \\
\hline $0.941(5) \mathrm{Pt}+0.059(5) \mathrm{Zn}$ & $0.25936(6)$ & $0.38357(5)$ & $88(2)$ & $90(2)$ & $105(2)$ & $8(2)$ & $94(1)$ \\
\hline $\mathrm{Zn}$ & $0.64377(18)$ & $0.43485(17)$ & $132(6)$ & $102(5)$ & $97(5)$ & $-9(4)$ & $111(3)$ \\
\hline \multicolumn{8}{|l|}{$\mathrm{HoPt}_{1.055(5)} \mathrm{Zn}_{0.945(5)}$} \\
\hline Ho & $0.04194(6)$ & $0.68525(7)$ & $31(2)$ & $89(2)$ & $70(2)$ & $-5(2)$ & $63(1)$ \\
\hline $0.983(5) \mathrm{Pt}+0.017(5) \mathrm{Zn}$ & $0.25193(5)$ & $0.37774(6)$ & $42(2)$ & $79(2)$ & $96(2)$ & $14(1)$ & $73(1)$ \\
\hline $0.927(4) \mathrm{Zn}+0.073(4) \mathrm{Pt}$ & $0.63836(14)$ & $0.43577(15)$ & $88(5)$ & $97(5)$ & $71(6)$ & $-11(4)$ & $85(4)$ \\
\hline \multicolumn{8}{|l|}{ ErPtZn } \\
\hline $\mathrm{Er}$ & $0.04238(6)$ & $0.68441(5)$ & $62(1)$ & $64(1)$ & $72(1)$ & $-4(1)$ & $66(1)$ \\
\hline $\mathrm{Pt}$ & $0.25150(5)$ & $0.37723(4)$ & $67(1)$ & $55(1)$ & $77(1)$ & $4(1)$ & $66(1)$ \\
\hline $\mathrm{Zn}$ & $0.63627(17)$ & $0.43711(14)$ & $86(4)$ & $64(4)$ & $68(4)$ & $-4(3)$ & $73(2)$ \\
\hline
\end{tabular}

tion counter with pulse height discrimination. Scans were taken in the $\omega / 2 \theta$ mode. Empirical absorption corrections were applied on the basis of $\psi$-scan data, accompanied by spherical absorption corrections. Details on the crystallographic data are given in Table 2.

\section{Structure refinements}

The four diffractometer data sets showed primitive orthorhombic lattices, and the extinction conditions were compatible with space group Pnma, in agreement with our previous results on CePtZn [23] and EuPtZn [13]. The atomic parameters of the europium compound were taken as starting values, and the four structures were refined using SHELXL-
97 [30] (full-matrix least-squares on $F^{2}$ ) with anisotropic atomic displacement parameters for all sites. The occupancy parameters were refined in separate series of least-squares cycles in order to check for deviations from the ideal composition. Only for ErPtZn all sites were fully occupied within two standard deviations. Similar to the series of $R E A u Z n$ compounds [21], for the remaining three crystals we also observed small degrees of $\mathrm{Pt} / \mathrm{Zn}$ mixing, which led to the refined compositions listed in Table 2. In the final cycles these mixed occupancies were refined as least-squares variables. The refined positional parameters and interatomic distances (exemplarily for ErPtZn) are listed in Tables 3 and 4.

Further details of the crystal structure investigation may be obtained from Fachinformationszentrum Karlsruhe, 
Table 4. Interatomic distances (pm) in the structure of ErPtZn. All distances within the first coordination shells are listed. Standard deviations are all equal or smaller than $0.2 \mathrm{pm}$.

\begin{tabular}{|c|c|c|c|c|c|}
\hline \multirow[t]{14}{*}{ Er: } & $1 \mathrm{Pt}$ & 287.6 & \multirow[t]{6}{*}{ Pt: } & $2 \mathrm{Zn}$ & 265.0 \\
\hline & $2 \mathrm{Pt}$ & 291.3 & & $1 \mathrm{Zn}$ & 267.0 \\
\hline & $2 \mathrm{Pt}$ & 293.4 & & $1 \mathrm{Zn}$ & 268.8 \\
\hline & $1 \mathrm{Zn}$ & 313.7 & & $1 \mathrm{Er}$ & 287.6 \\
\hline & $2 \mathrm{Zn}$ & 314.1 & & $2 \mathrm{Er}$ & 291.3 \\
\hline & $2 \mathrm{Zn}$ & 316.3 & & $2 \mathrm{Er}$ & 293.4 \\
\hline & $1 \mathrm{Zn}$ & 343.6 & \multirow[t]{8}{*}{$\mathrm{Zn}:$} & $2 \mathrm{Pt}$ & 265.0 \\
\hline & $2 \mathrm{Er}$ & 359.6 & & $1 \mathrm{Pt}$ & 267.0 \\
\hline & \multirow[t]{6}{*}{$2 \mathrm{Er}$} & 366.7 & & $1 \mathrm{Pt}$ & 268.8 \\
\hline & & & & $2 \mathrm{Zn}$ & 295.1 \\
\hline & & & & $1 \mathrm{Er}$ & 313.7 \\
\hline & & & & $2 \mathrm{Er}$ & 314.1 \\
\hline & & & & $2 \mathrm{Er}$ & 316.3 \\
\hline & & & & $1 \mathrm{Er}$ & 343.6 \\
\hline
\end{tabular}

76344 Eggenstein-Leopoldshafen, Germany (fax: +49-7247808-666; e-mail: crysdata@ fiz-karlsruhe.de, http://www.fizinformationsdienste.de/en/DB/icsd/depot_anforderung.html) on quoting the deposition numbers CSD-423114 $\left(\mathrm{PrPt}_{1.056}{ }^{-}\right.$ $\left.\mathrm{Zn}_{0.944}\right)$, CSD-423117 (GdPt $\left.0.941 \mathrm{Zn}_{1.059}\right)$, CSD-423116 $\left(\mathrm{HoPt}_{1.055} \mathrm{Zn}_{0.945}\right)$, and CSD-423115 (ErPtZn).

\section{Discussion}

The series of equiatomic REPtZn intermetallics has been completely characterized on the basis of powder $\mathrm{X}$-ray diffraction data. The members with $R E=\mathrm{Y}$, Pr, $\mathrm{Nd}$, and $\mathrm{Gd}-\mathrm{Tm}$ have been synthesized for the first time. These REPtZn compounds were prepared at high temperatures, i.e. 900 [13], 920 [23], 1070 [22, 24, 25], and 1120 (this work) K, followed by quenching. These samples all crystallize with the orthorhombic TiNiSitype [5] structure. With the exception of EuPtZn [13], the cell volumes decrease from the lanthanum to the

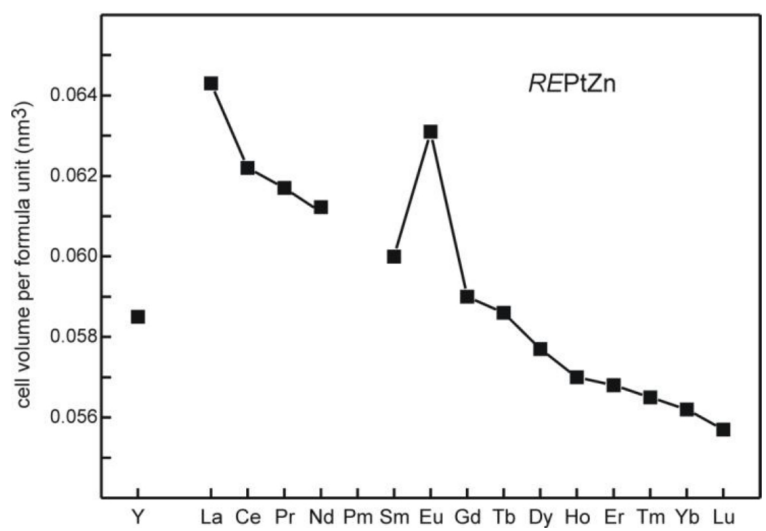

Fig. 1. Course of the cell volumes in the series of REPtZn compounds. lutetium compound as expected from the lanthanoid contraction. Due to the presence of divalent europium atoms, EuPtZn shows a positive deviation from this smooth curve (Fig. 1). The cell volume of YPtZn fits in between TbPtZn and DyPtZn. Similar to the series of $R E \mathrm{AuZn}$ compounds [21], we obtained no REPtZn representative with scandium.

Annealing of the REPtZn samples towards lower temperatures (from $1070 \mathrm{~K}$ to r. t. at a rate of $2 \mathrm{~K} \mathrm{~h}^{-1}$ ) leads to hexagonal phases with $\mathrm{ZrNiAl}$-type structure. However, there are distinct differences when compared with the $R E \mathrm{PdZn}$ series $[11,13,19]$. For the $R E \mathrm{PtZn}$ samples we observed distinct deviations from the ideal $1: 1: 1$ composition either through platinum vacancies or strong Pt/Zn mixing. Detailed studies on these lowtemperature phases are in progress.

Quenching of the REPtZn samples from high temperature might induce structural disorder. This is readily understandable for the TiNiSi type (space group Pnma), which is an ordered ternary version of $\mathrm{KHg}_{2}$ (space group Imma) [31]. Full platinum-zinc ordering has only been observed for the ErPtZn crystal. All other investigated crystals showed small homogeneity ranges, for $\mathrm{HoPt}_{1.055(5)} \mathrm{Zn}_{0.945(5)}$ even both $4 c$ sites were refined with mixed occupancies. Thus, small homogeneity ranges can be expected for all $R E P t Z n$ samples. The mixing observed here for the $R E \mathrm{Pt}_{1 \pm x} \mathrm{Zn}_{1 \pm x}$ samples is slightly smaller than for the $R E \mathrm{Au}_{1 \pm x} \mathrm{Zn}_{1 \pm x}$ compounds [21]. The lattice parameters of the single crystals and of the bulk powders agree well (Table 1). The Pt/Zn mixing has only little influence.

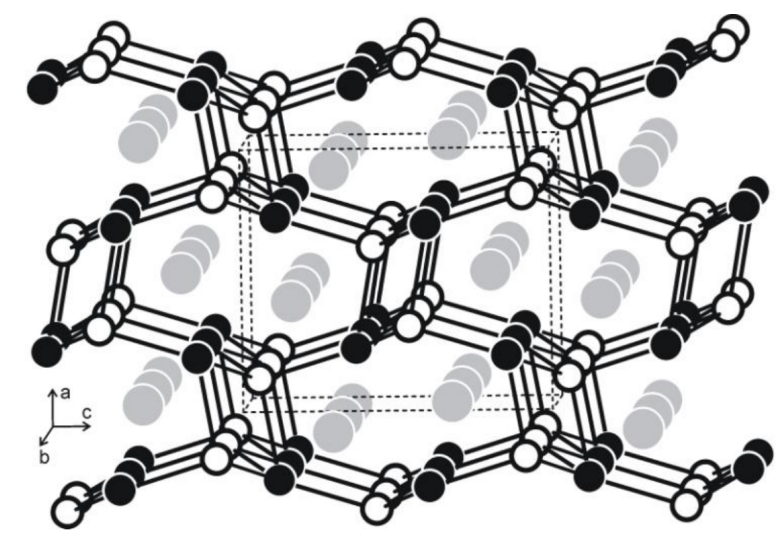

Fig. 2. View of the ErPtZn structure approximately along the $b$ axis. Erbium, platinum, and zinc atoms are drawn as medium grey, black filled and open circles, respectively. The three-dimensional [PtZn] network is emphasized. 


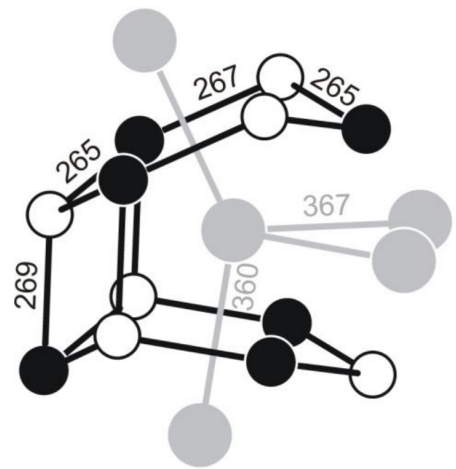

Fig. 3. Near-neighbor coordination of the erbium atoms in ErPtZn. Erbium, platinum, and zinc atoms are drawn as medium grey, black filled and open circles, respectively. The puckered $\mathrm{Pt}_{3} \mathrm{Zn}_{3}$ hexagons are emphasized, and relevant interatomic distances are indicated.

As an example for the REPtZn series we discuss the ErPtZn structure, where no mixing was observed. In Fig. 2 we present a view of the ErPtZn structure approximately along the $b$ axis. The platinum and zinc atoms build up a three-dimensional [PtZn] network with $\mathrm{Pt}-\mathrm{Zn}$ distances ranging from 265 to $269 \mathrm{pm}$, slightly longer than the sum of the covalent radii [32] of $254 \mathrm{pm}$. Within the network the platinum atoms have distorted tetrahedral zinc coordination and vice versa. These $\mathrm{PtZn}_{4 / 4}$, respectively $\mathrm{ZnPt}_{4 / 4}$ tetrahedra share common corners within the network.

The TiNiSi-type structure of ErPtZn derives from the well known $\mathrm{AlB}_{2}$ structure. The erbium atoms take the aluminum position, and the platinum and zinc atoms order on the boron network. The resulting $\mathrm{Pt}_{3} \mathrm{Zn}_{3}$ hexagons are strongly puckered, leading to the erbium coordination shown in Fig. 3. The platinum atoms are the nearest neighbors to erbium. The five short Er-Pt distances range from 288 to $293 \mathrm{pm}$, close to the sum of the covalent radii of $286 \mathrm{pm}$ [32]. The puckering of the $\mathrm{Pt}_{3} \mathrm{Zn}_{3}$ hexagons leads to interlayer Pt-Zn distances of $269 \mathrm{pm}$. Between the layers we observe formation of $\mathrm{Pt}_{2} \mathrm{Zn}_{2}$ rhombs in a laddertype arrangement. The platinum atoms as the most electronegative components of ErPtZn show a maximum distance $(401 \mathrm{pm})$ within these rhombs. By contrast, we observe somewhat shorter $\mathrm{Zn}-\mathrm{Zn}$ distances of $295 \mathrm{pm}$, which compare with the longer $\mathrm{Zn}-\mathrm{Zn}$ distances in $h c p$ zinc $(6 \times 266$ and $6 \times 291 \mathrm{pm})$ [33]. Each erbium atom has four nearest erbium neighbors at $360(2 \times)$ and $367(2 \times)$ pm, only slightly longer than in $h c p$ erbium $(6 \times 356$ and $6 \times 347 \mathrm{pm})$ [33].

\section{Acknowledgements}

This work was financially supported by the Deutsche Forschungsgemeinschaft. T. M. is indebted to the Forschungsschule Molecules and Materials - A Common Design Principle for a PhD stipend.
[1] P. Villars, K. Cenzual, Pearson's Crystal Data: Crystal Structure Database for Inorganic Compounds, (release 2009/10), ASM International@, Materials Park, Ohio, 2009.

[2] P. I. Krypyakevich, V. Ya. Markiv, E. V. Melnyk, Dopov. Akad. Nauk. Ukr. RSR, Ser. A, 1967, 750.

[3] A. E. Dwight, M. H. Mueller, R. A. Conner, Jr., J. W. Downey, H. Knott, Trans. Met. Soc. AIME 1968, 242, 2075.

[4] M. F. Zumdick, R.-D. Hoffmann, R. Pöttgen, Z. Naturforsch. 1999, 54b, 45.

[5] C. B. Shoemaker, D. P. Shoemaker, Acta Crystallogr. 1965, 18,900 .

[6] A. Szytuła, J. Leciejewicz, Handbook of Crystal Structures and Magnetic Properties of Rare Earth Intermetallics, CRC Press, Boca Raton, Florida, 1994.

[7] G. A. Landrum, R. Hoffmann, J. Evers, H. Boysen, Inorg. Chem. 1998, 37, 5754.

[8] G. Nuspl, K. Polborn, J. Evers, G. A. Landrum, R. Hoffmann, Inorg. Chem. 1996, 35, 6922.

[9] G. J. Miller, Eur. J. Inorg. Chem. 1998, 523.
[10] U.Ch. Rodewald, B. Chevalier, R. Pöttgen, J. Solid State Chem. 2007, 180, 1720.

[11] A. Iandelli, J. Alloys Compd. 1992, 182, 87.

[12] R. Mishra, R. Pöttgen, R.-D. Hoffmann, D. Kaczorowski, H. Piotrowski, P. Mayer, C. Rosenhahn, B. D. Mosel, Z. Anorg. Allg. Chem. 2001, 627, 1283.

[13] T. Mishra, W. Hermes, T. Harmening, M. Eul, R. Pöttgen, J. Solid State Chem. 2009, 182, 2417.

[14] D. Johrendt, G. Kotzyba, H. Trill, B. D. Mosel, H. Eckert, Th. Fickenscher, R. Pöttgen, J. Solid State Chem. 2002, 164, 201.

[15] R. Pöttgen, J. Mater. Chem. 1995, 5, 505.

[16] R. Pöttgen, J. Mater. Chem. 1996, 6, 63.

[17] P. Solokha, S. De Negri, A. Saccone, V. Pavlyuk, J.-C. Tedenac, Z. Anorg. Allg. Chem. 2007, 633, 482.

[18] W. Hermes, R. Mishra, U.Ch. Rodewald, R. Pöttgen, Z. Naturforsch. 2008, 63b, 537.

[19] W. Hermes, R. Mishra, H. Müller, D. Johrendt, R. Pöttgen, Z. Anorg. Allg. Chem. 2009, 635, 660.

[20] M. L. Fornasini, A. Iandelli, F. Merlo, M. Pani, Intermetallics 2000, 8, 239. 
[21] T. Mishra, R. Pöttgen, Intermetallics 2011, 19, 947.

[22] S. K. Dhar, R. Kulkarni, P. Manfrinetti, M. Pani, Y. Yonezawa, Y. Aoki, Phys. Rev. B 2007, 76, 054411.

[23] R. Mishra, W. Hermes, R. Pöttgen, Z. Naturforsch. 2007, 62b, 1581.

[24] S. K. Dhar, R. Kulkarni, H. Hidaka, Y. Toda, H. Kotegawa, T.C. Kobayashi, P. Manfrinetti, A. Provino, J. Phys.: Condens. Matter 2009, 21, 156001.

[25] P. D. Kulkarni, S. K. Dhar, A. Provino, P. Manfrinetti, A. K. Grover, Phys. Rev. B 2010, 82, 144411.

[26] W. Hermes, T. Harmening, R. Pöttgen, Chem. Mater. 2009, 21, 3325.

[27] R. Pöttgen, Th. Gulden, A. Simon, GIT Labor-Fachzeitschrift 1999, 43, 133.
[28] R. Pöttgen, A. Lang, R.-D. Hoffmann, B. Künnen, G. Kotzyba, R. Müllmann, B. D. Mosel, C. Rosenhahn, Z. Kristallogr. 1999, 214, 143.

[29] K. Yvon, W. Jeitschko, E. Parthé, J. Appl. Crystallogr. 1977, 10, 73 .

[30] G. M. Sheldrick, SHELXL-97, Program for the Refinement of Crystal Structures, University of Göttingen, Göttingen (Germany) 1997. See also: G. M. Sheldrick, Acta Crystallogr. 2008, A64, 112.

[31] R.-D. Hoffmann, R. Pöttgen, Z. Kristallogr. 2001, 216, 127.

[32] J. Emsley, The Elements, Oxford University Press, Oxford, 1999.

[33] J. Donohue, The Structures of the Elements, Wiley, New York, 1974. 